\title{
Determination of Sulfur in Milligram Steel Samples by Cathodic Stripping Voltammetry
}

\author{
Tatsuhiko Tanaka ${ }^{\dagger}$, Koichi Tsuyuki, Takashi IshiYama, \\ Gishin Takımoto and Atsushi Mizuike
}

Faculty of Engineering, Science University of Tokyo, Kagurazaka, Shinjuku 162, Japan

\begin{abstract}
Sulfur at the $\mu \mathrm{g} \mathrm{g}^{-1}$ level in 1-mg steel samples is determined by cathodic stripping voltammetry (CSV) with a silver disk electrode, after conversion of the sulfur into hydrogen sulfide followed by its absorption in a $0.2 \mathrm{M}$ sodium hydroxide solution. Microscale operations with microliter volumes of solutions are used throughout the entire procedure, except for CSV. Simple apparatus have been devised for a safe treatment with perchloric acid and for the evolution of hydrogen sulfide by reducing with a mixture of hydroiodic and phosphinic acids. The proposed method can be applied to the determination of 60 to $200 \mu \mathrm{g} \mathrm{g}^{-1}$ of sulfur in steels with an RSD of ca. 5\% ( $n=3$ to 10). The time required for a determination is less than $2.5 \mathrm{~h}$.
\end{abstract}

Keywords Sulfur, steel, microscale preconcentration technique, cathodic stripping voltammetry, silver disk electrode

Previously, the authors established a reliable method for the determination of sulfide at the low $\mathrm{n} \mathrm{ml}^{-1}$ level in sodium hydroxide solutions by cathodic stripping voltammetry (CSV) with a silver disk electrode. ${ }^{1}$ The present paper reports on the application of this method to the determination of sulfur in steel after the evolution of hydrogen sulfide followed by absorption in a $0.2 \mathrm{M}$ sodium hydroxide solution. A mixture of hydroiodic and phosphinic acids ${ }^{2}$ was used for the reduction of sulfate to sulfide.

The determination of sulfur in iron and steel is usually performed with gram samples by gravimetric, spectrophotometric, gas analytical, and emission spectrometric methods. Because of its intrinsic high sensitivity, the CSV method is easily applied to sulfur at the $\mu \mathrm{g} \mathrm{g}^{-1}$ level in 1-mg steel samples, in combination with a microscale preconcentration technique operated with microliter volumes of solutions. The advantages of microscale techniques include: (1) economization of samples and high-purity reagents, (2) minimization of experimental wastes, (3) reduction of bench space, (4) rapidity and (5) safety.

\section{Experimental}

\section{Apparatus}

Perchloric acid was evaporated in the chamber shown in Fig. 1. Most of perchloric acid fumes were condensed on the inside of the chamber; the remainder was

$\dagger$ To whom correspondence should be addressed.

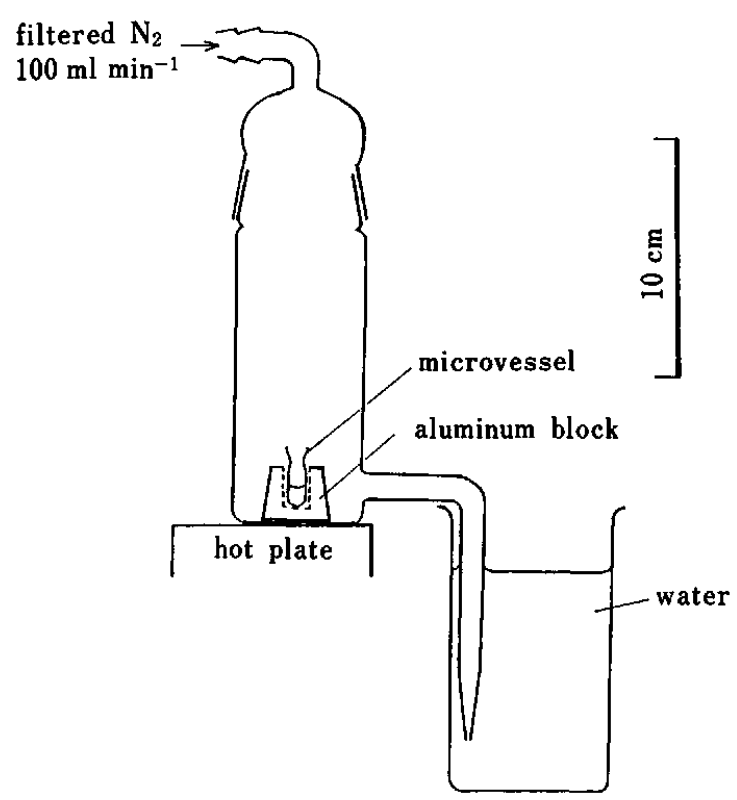

Fig. 1 Pyrex evaporation chamber.

completely trapped in water by carefully adjusting the nitrogen flow rate. Figure 2 shows the quartz apparatus used for the evolution of hydrogen sulfide. A wet gauze replaced the conventional reflux condenser. The same quartz microvessel $(c a .500 \mu \mathrm{l})$ was used throughout the procedure from sample decomposition to hydrogen sulfide evolution.

Stripping voltammograms were recorded with a 


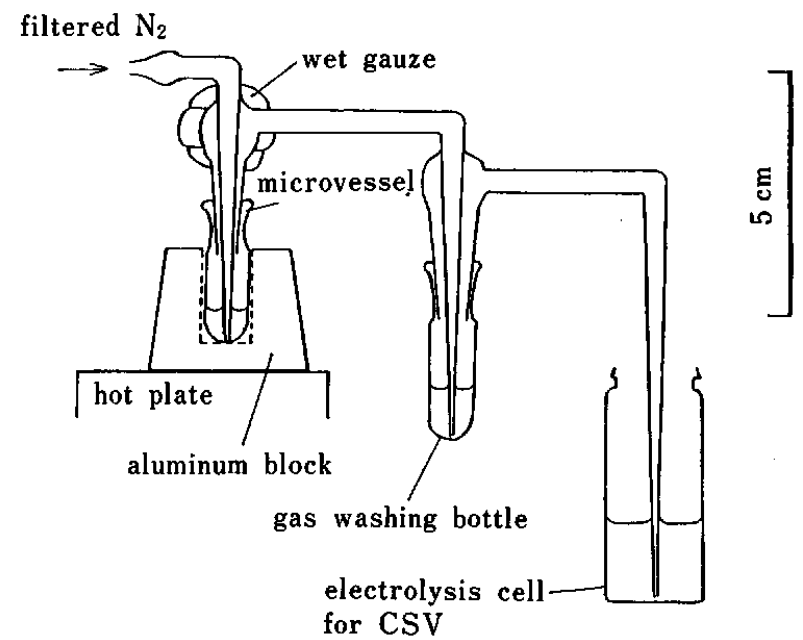

Fig. 2 Quartz apparatus for hydrogen sulfide evolution.

Yanaco P-1100 polarograph with an AST-100 stripping timer (Yanagimoto, Kyoto) and a WX2400 XY recorder (Graphtec, Tokyo). A silver disk electrode $\left(20 \mathrm{~mm}^{2}\right.$ area) was prepared as described previously. ${ }^{1}$ The oxide film on the silver electrode surface should be daily removed by holding it at $-1.6 \mathrm{~V} v s$. the saturated calomel electrode (SCE) for $10 \mathrm{~min}$.

\section{Reagents}

Analytical-grade reagents were used without further purification. Water was distilled from a vitreous silica sub-boiling still.

Reducing reagent solution. A 4-to-1 mixture of hydroiodic (55-58\%) and phosphinic (ca. 50\%) acids in a 200$\mathrm{ml}$ quartz round-bottomed flask was boiled gently for $2 \mathrm{~h}$ at $c a .120^{\circ} \mathrm{C}$ with an electric heating mantle in a nitrogen stream at a flow rate of $100 \mathrm{ml} \mathrm{min}^{-1}$ to remove traces of sulfur as hydrogen sulfide. The purified solution was stored in a brown-colored glass bottle.

Standard sulfide solution. About $3 \mathrm{~g}$ of sodium sulfide nonahydrate was daily dissolved in a $0.2 \mathrm{M}$ sodium hydroxide solution. The solution ( $c a .4 \mathrm{mg} \mathrm{ml}^{-1} \mathrm{~S}$ ) was standardized iodometrically, and then diluted 1000 -fold with a $0.2 \mathrm{M}$ sodium hydroxide solution.

Standard sulfate solution. A sulfate stock solution (ca. $5 \mathrm{mg} \mathrm{ml}^{-1} \mathrm{~S}$ ) was prepared from potassium sulfate, previously dried at $110^{\circ} \mathrm{C}$ for $2 \mathrm{~h}$. The solution was diluted to 0.5 to $3 \mathrm{ng} \mathrm{hl}^{-1}$ with water immediately before use.

Sulfur-free iron solution $\left(10 \mathrm{mg} \mathrm{ml}^{-1} \mathrm{Fe}\right)$. One gram of high-purity iron \{JSS (The Iron and Steel Institute of Japan) 001-1, S: $\left.2 \mu \mathrm{g} \mathrm{g}^{-1}\right\}$ was decomposed with $7.5 \mathrm{ml}$ of $6 \mathrm{M}$ hydrochloric acid by heating and boiled gently for ca. $10 \mathrm{~min}$ in order to remove traces of sulfur as much as possible. To the solution was added $7.5 \mathrm{ml}$ of nitric acid drop by drop to oxidize iron(II); the solution was then boiled in order to expel nitrogen oxides. The solution was then diluted to $100 \mathrm{ml}$ with water.

Gas washing solution. Three volumes of hydrochloric acid $(1+60)$ were mixed with one volume of $0.5 \%(\mathrm{w} / \mathrm{v})$ hydrazinium $(2+)$ chloride immediately before use.

\section{Recommended procedure}

Weigh, to the nearest $0.01 \mathrm{mg}, 0.5-1.5 \mathrm{mg}$ of steel into the microvessel. Decompose the weighed sample completely with $15 \mu 1$ of a 1-to-1 hydrochloric-nitric acid mixture, with slight heating if necessary. When representative (average) sulfur concentrations in heterogeneous steel samples are required, decompose $1 \mathrm{~g}$ of steel with $15 \mathrm{ml}$ of the acid mixture, dilute the solution to $100 \mathrm{ml}$ with water, and then transfer a $100-\mu \mathrm{l}$ aliquot (containing $1 \mathrm{mg} \mathrm{Fe}$ ) into the microvessel. For preparing the calibration curve, mix $100 \mu \mathrm{l}$ of a sulfur-free iron solution (containing $1 \mathrm{mg} \mathrm{Fe}$ ) with $100 \mu \mathrm{l}$ of standard sulfate solutions (containing 40 to $320 \mathrm{ng} \mathrm{S}$ ).

Add $100 \mu \mathrm{l}$ of perchloric acid $(60-62 \%)$ to the solution in the microvessel in the evaporation chamber shown in Fig. 1, and heat on a hot plate until perchloric acid fumes appear in order to remove nitric acid. Cool, add $10 \mu \mathrm{l}$ of hydrochloric acid, and evaporate to dryness. Cool, and dissolve the residue in $10 \mu \mathrm{l}$ of hydrochloric acid.

Then, cool the solution to room temperature, add $50 \mu \mathrm{l}$ of the reducing reagent solution, and allow to stand for ca. $5 \mathrm{~min}$ to reduce iodine, produced by pre-reduction of iron(III), with phosphinic acid. Set this microvessel in the distillation apparatus (Fig. 2). Place $250 \mu \mathrm{l}$ of fresh washing solution in the gas washing bottle and $4 \mathrm{ml}$ of $0.2 \mathrm{M}$ sodium hydroxide solution in the electrolysis cell. Add another $50-\mu \mathrm{l}$ portion of the reducing reagent solution to the microvessel washing the inside completely, and heat at $110^{\circ} \mathrm{C}$ for $30 \mathrm{~min}$ in a nitrogen stream at a flow rate of $10 \mathrm{ml} \mathrm{min}^{-1}$ to evolve hydrogen sulfide and collect it in the $0.2 \mathrm{M}$ sodium hydroxide solution.

Fit the electrode assembly for CSV into the electrolysis cell, and deaerate the sample solution. Then cover the solution surface with nitrogen. Stop the deaeration and continue the purging with nitrogen throughout the entire procedure. Rotate the silver electrode at $2.0 \times 10^{3} \mathrm{rpm}$ and preelectrolyze to deposit sulfide onto the electrode at $-0.4 \mathrm{~V} v \mathrm{~s}$. SCE for $5 \mathrm{~min}$. Stop the electrode rotation. After $10 \mathrm{~s}$, scan the electrode potential from -0.4 to $-1.5 \mathrm{~V} v s$. SCE at $100 \mathrm{mV} \mathrm{s}^{-1}$ and record a currentvoltage curve by the differential pulse mode, using a pulse amplitude of $100 \mathrm{mV}$, pulse duration of $50 \mathrm{~ms}$, and pulse repetition time of $100 \mathrm{~ms}$.

\section{Results and Discussion}

The evaporation chamber (Fig. 1) was useful for minimizing airborne contamination as well as safely expelling perchloric acid fumes. The gauze (Fig. 2) wetted with water before each experiment sufficed to attain a complete reflux condensation.

Typical differential pulse cathodic stripping voltammograms are shown in Fig. 3. The shape of the voltammogram for an iron sample was the same as that for a standard sulfide solution. Compared with mer- 


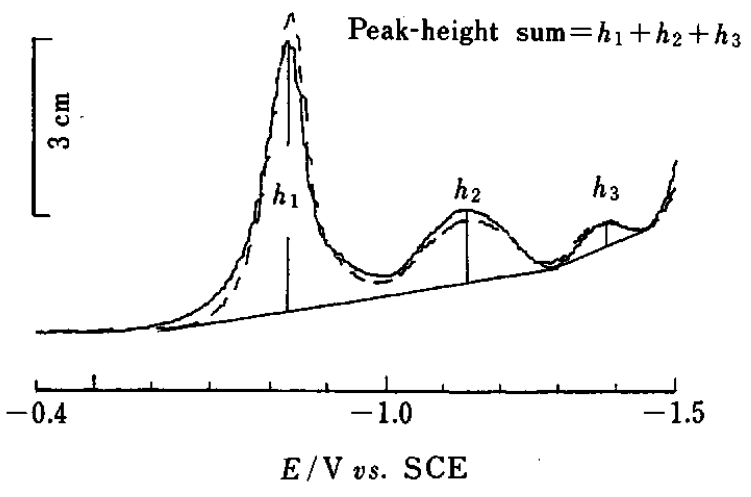

Fig. 3 Typical differential pulse cathodic stripping voltammograms. S concentration: $49 \mathrm{ng} \mathrm{ml}^{-1}$. -: iron sample; the whole procedure was carried out. ---: standard sulfide solution.

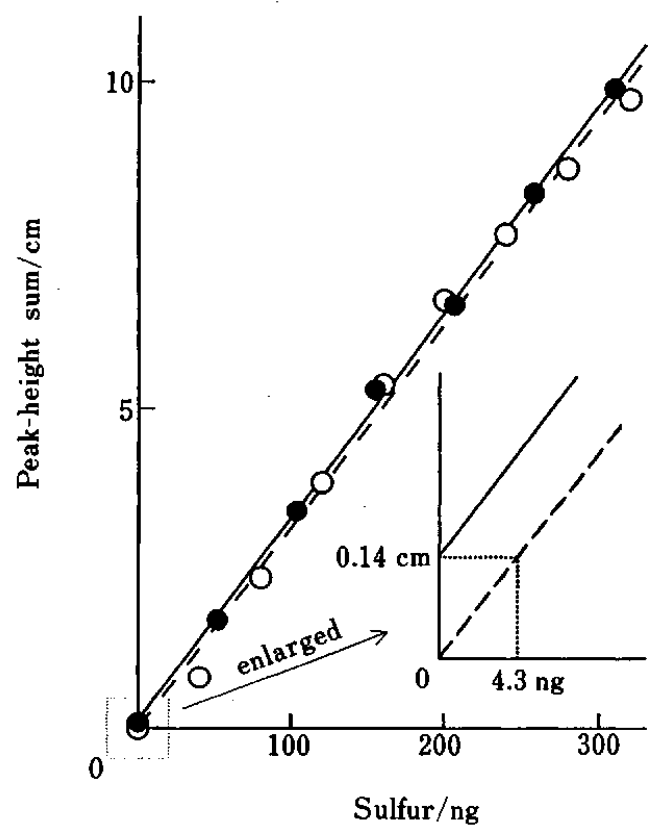

Fig. 4 Calibration curves. (O) The CSV alone was performed with standard sulfide solutions. (O) The whole procedure was performed with sulfur-free iron solutions containing $1 \mathrm{mg} \mathrm{Fe}$ and standard sulfate solutions.

cury working electrodes, silver electrodes were easier to use and the sum of the heights of all the stripping peaks was proportional to the sulfide concentration, though the detection limits for sulfide were slightly higher and several underpotential stripping peaks were obtained. ${ }^{1}$ Figure 4 shows the calibration curves (peak-height sum vs. concentration) obtained by carrying out the entire procedure and the CSV of only sulfide. Both curves were linear up to at least $300 \mathrm{ng}$ of sulfur and parallel to each other. The blank value, ca. $4 \mathrm{ng}$ of sulfur, was quite reproducible. The day-to-day variation of the calibration curve was within an RSD of $c a .8 \%$.
Table 1 Determination of sulfur in steel (I)

\begin{tabular}{|c|c|c|}
\hline Sample $^{a}$ & \multicolumn{2}{|c|}{$\mathrm{S}$ in sample $/ \mu \mathrm{g} \mathrm{g}^{-1}$} \\
\hline JSS $240-8(0.006 \%)^{b}$ & $59,56,51,51,54$ & $\begin{array}{ll}\text { Av. } & 54 \\
\text { SD } & 3.4\end{array}$ \\
\hline JSS 066-1 $(0.011 \%)^{b}$ & $106,103,112$ & $\begin{array}{l}\text { Av. } 107 \\
\text { SD } \quad 4.6\end{array}$ \\
\hline JSS $241-9(0.0197 \%)^{b}$ & $\begin{array}{l}215,192,192,189,183 \\
192,192,196,192,189\end{array}$ & $\begin{array}{lr}\text { Av. } & 193 \\
\text { SD } & 8.4\end{array}$ \\
\hline
\end{tabular}

a. Aliquots $(100 \mu l)$ taken from a solution prepared by dissolving $1 \mathrm{~g}$ of the steel sample. b. Certified value.

Table 2 Determination of sulfur in steel (II)

\begin{tabular}{cccc}
\hline Sample & $\begin{array}{c}\text { Sample taken/ } \\
\mathrm{mg}\end{array}$ & $\begin{array}{c}\text { S determined/ } \\
\mathrm{ng}\end{array}$ & $\begin{array}{c}\text { S in sample/ } \\
\mu \mathrm{g} \mathrm{g}^{-1}\end{array}$ \\
\hline JSS 240-8 & 1.46 & 87 & 60 \\
$(0.006 \%)^{\mathrm{a}}$ & 1.21 & 68 & 56 \\
& 1.57 & 87 & 55 \\
& & & Av. $57 \mu \mathrm{g} \mathrm{g}^{-1}$ \\
& & & SD $2.6 \mu \mathrm{g} \mathrm{g}^{-1}$ \\
JSS 241-9 & 0.99 & 207 & 209 \\
$(0.0197 \%)^{\mathrm{a}}$ & 1.14 & 223 & 196 \\
& 1.04 & 207 & 199 \\
& 1.27 & 258 & 203 \\
& 0.60 & 116 & 193 \\
& & & Av. $200 \mu \mathrm{g} \mathrm{g}^{-1}$ \\
& & & SD $6.2 \mu \mathrm{g} \mathrm{g}^{-1}$ \\
\hline
\end{tabular}

a. Certified value.

Tables 1 and 2 summarize the analytical results obtained by the proposed method. A complete reduction of sulfate to sulfide in the presence of 0.5 to $1.5 \mathrm{mg}$ of iron was confirmed separately. The results were in good agreement with the certified values. The RSDs (ca. 5\%) of the analytical results for $1-\mathrm{mg}$ aliquots taken from $1-\mathrm{g}$ samples (Table 1) were nearly equal to those for separately taken 1-mg samples (Table 2), which indicates that sulfur was homogeneously distributed in these samples. The time required for a determination was less than $2.5 \mathrm{~h}$. The precision and accuracy of analytical results were approximately equal to those by ordinary scale operations.

\section{References}

1. T. Tanaka, T. Ishiyama and A. Mizuike, Anal. Sci., 8, 281 (1992).

2. JIS G 1215, "Methods for Determination of Sulfur in Iron and Steel", Japanese Industrial Standards Committee, Tokyo, 1982.

(Received March 25, 1993)

(Accepted July 8, 1993) 